\title{
Vitamin D3 and its receptor in selected obstetrical complications
}

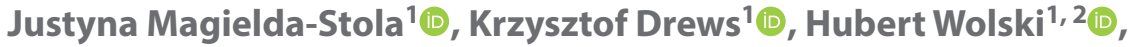 \\ Agnieszka Seremak-Mrozikiewicz' ${ }^{1}$ (1)
}

${ }^{1}$ Division of Perinatology and Women's Disease, Poznan University of Medical Sciences, Poznan, Poland

${ }^{2}$ Division of Obstetrics and Gynecology, Hospital Zakopane, Poland

\begin{abstract}
Vitamin D3 (VD3) and its steroidal nuclear receptor are necessary for proper development of a pregnancy. They play a key role in implantation, modulate the mother's immune response to the developing fetus, influence the final development of a placenta, and regulate blood pressure and glucose tolerance. VD3 deficiency can lead to the occurrence of obstetric complications such as recurrent miscarriages, preeclampsia, intrauterine growth restriction, gestational diabetes and preterm labor. VD3 deficiency is a common phenomenon across the globe; because of the higher demand placed on their bodies, pregnant women are more likely to develop VD3 deficiency. During pregnancy, VD3 supplementation is a safe method of treatment without risk of side effects or intoxication. To obtain the greatest efficacy, VD3 supplementation should start at the pregnancy planning stage, under control of the VD3 serum concentration, which should exceed $30 \mathrm{ng} / \mathrm{mL}$ ( $75 \mathrm{nmol} / \mathrm{L}$ ); this is to start the positive effect of the optimal VD3 concentration from the beginning of a pregnancy.
\end{abstract}

Key words: vitamin D; VDR; pregnancy complications

Ginekologia Polska 2021; 92, 6: 460-465

\section{INTRODUCTION}

Vitamin D (VD) has two main forms: Vitamin D2 (VD2), produced by plants, and VD3, produced under influence of UVB radiation in animal skin. They both have the same biological action and vary only in their side-chain structure. Because of its pleiotropic actions, VD3 plays an important role in the human body. The discovery of VD3 was a result of the investigation on the cause of rickets at the beginning of the $20^{\text {th }}$ century. In recent years available data suggests a connection between low levels of VD3 and the development of cancers, and cardiovascular and autoimmune diseases [1].

VD3 is synthesised from 7-dehydrocholesterol in the cortical layer of the epidermis under the influence of 290$-315 \mathrm{~nm}$ wavelength UVB radiation. Many factors such as geographic location, season, air pollution, skin colour, and age affect VD3 synthesis. The largest amount of UVB radiation able to induce synthesis of VD3 occurs around the equator, and it decreases when approaching the poles. In Poland, VD3 synthesis is almost impossible from October to March, and in the remaining months, $60 \%$ of the UVB radiation able to induce synthesis of VD3 occurs between 11 AM and 3 PM. VD3 is a secosteroid prohormone which undergoes activation by 25 -hydroxylation and 1a-hydroxylation, respectively, in the liver and the kidneys as well as in other tissues. The active form of VD3, $1.25(\mathrm{OH}) \mathrm{D} 3$, is known as calcitriol. Serum VD3 level is measured based on the 25(OH)D3 concentration because it has a half-life 1000 times higher than 1.25(OH)D3. Calcitriol affects target cells after binding with the specific steroidal VD receptor (VDR). After binding with calcitriol, VDR creates a heterodimer with retinoid receptor $X(R X R)$ which binds with VD responsive elements on DNA (VDRE), affecting transcription of many genes [2].

It is accepted that the minimal $25(\mathrm{OH}) \mathrm{D} 3$ serum level which enables optimal functioning of the human body is $30 \mathrm{ng} / \mathrm{mL}$ ( $75 \mathrm{nmol} / \mathrm{L})$. This concentration was based on the dependence of the VD3 and parathormone concentration, intestinal calcium absorption and bone density measurements. VD3 deficiency can affect about $30 \%$ of the world's population. In Poland, the study of Płudowski et al. [3], from 
2014 showed that almost $90 \%$ of the investigated population had a 25(OH)D3 level below the optimal $30 \mathrm{ng} / \mathrm{mL}$ level.

VD3 influences pregnancy development from the time of implantation. An increase in calcitriol concentration is observed from 10-12 weeks of gestation and grows twoto threefold until the end of pregnancy [4]. A large part of this increase is due to the expression of 1a-hydroxylase in the chorion and placenta [5]. Calcitriol helps in the transformation of endometrial cells into decidual cells, promotes a human trophoblast invasion in vitro, and increases the expression of HOXA10, a gene necessary in the implantation process, and marrow differentiation in early gestation [6]. The expression of VDR and CYP27B1 in the chorion and placenta is greatest in the first and second trimesters, which proves the high demand for VD3 at the beginning of the pregnancy [7]. In the maintenance of a proper pregnancy, a state of transient immunosuppression is necessary, so the mother's immune system does not reject foreign antigens of the embryo and the fetus. VD3 modulates actions of the immune system by regulating synthesis of cytokines and inhibiting proliferation of pro-inflammatory cells. Calcitriol directly influences the naive CD4+ lymphocytes, inhibiting their differentiation into Th1 lymphocytes (synthesis of pro-inflammatory cytokines such as IFNY), while promoting differentiation into Th2 lymphocytes (synthesis of anti-inflammatory such as IL-4, IL-5, IL-10). VD3 also inhibits lymphocyte $B$ synthesis and production of immunoglobulin type G. In a human syncytiotrophoblast, VD3 regulates, in an autocrine manner, synthesis of human chorionic gonadotropin (hCG), human placental lactogen (hPL), estradiol, and progesterone. These hormones help pregnancy to develop and stimulate growth and development of the placenta $[8,9]$.

\section{VD3 AND RECURRENT PREGNANCY LOSS}

In recent years, the importance of impaired function of the immune system in the physiopathology of recurrent pregnancy loss (RPL) is being increasingly recognised. There is elevation of NK CD56+ cells as a percentage of total peripheral lymphocytes in the serum of women with recurrent pregnancy loss [10]. Also, there is a strong immunological response of Th1 lymphocytes, which produce pro-inflammatory cytokines and increase cytotoxicity of NK cells [11].

VD3, because of its immunomodulatory potential, can exert a positive effect on implantation and development of early gestation. A meta-analysis from 2018, which included 2700 women (11 studies), assessed the influence of VD3 concentration on assisted reproductive treatment. In this study, VD3 concentration higher than $30 \mathrm{ng} / \mathrm{mL}$ was associated with greater chances of getting a positive pregnancy test, clinical pregnancy and giving birth to a healthy newborn. Therefore, investigators highlight the possible positive effects of VD3 supplementation in groups of women who undergo assisted reproductive treatment [12]. The study of Ota et al. [13], conducted on a group of 133 women with a history of three or more pregnancy losses, has shown that $47.7 \%$ of women had VD3 deficiency, which was correlated with increased cell immunity and autoimmunization. Similar results were obtained by Chen et al. [14], in a group of 99 women with a history of recurrent pregnancy loss, when VD3 deficiency was measured in $64.6 \%$ of the cases and was associated with an adverse immunological profile: increased concentration of the Thelper lymphocytes synthesizing TNF a, lymphocytes CD19+ and NK cells. Moreover, in this study, supplementation of calcitriol ( $0.5 \mathrm{ug})$ for two months was reversing an adverse immunological profile. Expression of VDR in the endometrium of women with recurrent pregnancy loss was also analysed. The study of Tavakoli et al. did not show any difference in the expression of VDR in the endometrium of the women with recurrent pregnancy loss in comparison to the healthy controls [15]. In two other studies, chorion expression of VDR was lower in women with a history of recurrent pregnancy loss in comparison to healthy controls $[16,17]$. The European Society of Human Reproduction and Embryology, in recommendations from 2018 regarding recurrent pregnancy loss, advises prophylactic VD3 supplementation, although it does not advise routine determination of serum concentration of 25(OH)D3 [18].

Although there is no randomised control trial (RCT) on the effectiveness of VD3 supplementation in the prevention of miscarriages, most data suggest that it has positive effect of immunological profile, which promotes implantation and development of early gestation.

\section{VD3 and preeclampsia}

In Scandinavia, more frequent occurrence of preeclampsia (PE) in the winter months was observed, this later being proved in many population studies. This correlation was explained by the local lower skin synthesis of VD3 in the winter months [19]. Nowadays, many observational studies and meta-analyses are showing that low maternal VD3 serum concentration is related with greater risk of PE. In a meta-analysis from 2018 which included 23 studies, a serum level of $25(\mathrm{OH}) D 3$ below $20 \mathrm{ng} / \mathrm{mL}$ was associated with greater risk of PE [20]. VD3 can also affect blood pressure by inhibiting renin synthesis by the kidney capsular apparatus which was shown in the in vitro study [21]. Growth and development of the placenta is affected by VD3, and its deficiency is associated with $\mathrm{PE}$, simultaneously in $\mathrm{PE}$, placental synthesis of VD3 is decreased. Trophoblasts isolated from women with PE had only $1 / 10^{\text {th }}$ the activity of 1a hydroxylase in comparison to the trophoblasts isolated from healthy controls [22]. VDR expression is also signifi- 
cantly lower in placentas from women with PE [23]. There were several studies on the effects of VD3 supplementation on PE occurrence. In a meta-analysis conducted by Fogacci et al. [24] in 2019, supplementation of VD3 significantly reduced the risk of PE OR $(0.37,95 \% \mathrm{Cl}: 0.26,0.52)$. A Cochrane meta-analysis, also from 2019, showed that VD3 only supplementation decreases the risk of PE (RR 0.48, four studies conducted on a group of 499 women) [25]. Most data suggest that VD3 reduces the risk of PE in the general population. Royal College of Obstetricians and Gynaecologists for women with high risk of $P E$ advises intake of at least 800 IU daily combined with calcium [26].

\section{VD3 and fetal growth}

VD deficiency can disturb the process of formation and growth of the placenta, which can subsequently lead to intrauterine growth restriction (IUGR). In placentas from pregnancies complicated by IUGR, lower expression of VDR was observed [27]. Studies focused on proving the correlation between VD3 deficiency and higher IUGR occurrence have not found clear results. Some, like a study from 2019 conducted in Iran on a group of 812 women [28], or a multicenter study conducted on a group of 2,146 women from the USA [29], have shown that VD3 deficiency was associated with lower body weight in the newborns - a meta-analysis from 2013 showed such a correlation [30]. However, a study conducted in Norway in a group of 712 women from different ethnic groups showed that VD3 is not an independent factor affecting differences between them in anthropometric parameters of the newborns and birth weight [31]. There is also inconsistency in data about the effects of VD3 supplementation on birth weight. Two meta-analyses have shown that VD3 supplementation increases mean birth weight of newborns and decreases the risk of small for gestational age fetus (SGA) [32, 33]. On the other hand, the opposite result was found by Roth et al. [34], in an RCT conducted in Bangladesh on different doses of VD3 supplementation during pregnancy and lactation. There were no effects on height and birth weight of the newborns, or SGA occurrence in any of the tested groups. However, in this study supplementation was started between 17 and 24 weeks of gestation, which might be too late to obtain a maximal positive effect of optimal VD3 level on pregnancy development.

It is controversial whether VD3 supplementation has a positive effect on birth weight. Further studies are needed in order to help explain current contradictions within the existing body of knowledge.

\section{VD3 and gestational diabetes}

VD3 plays an important role in carbohydrate metabolism; a positive correlation between VD3 concentration and tissue insulin sensitivity has been shown. VD3 deficiency diminishes insulin secretion by pancreatic $\beta$ cells [35]. The insulin gene has a VDRE in a promoter region, so calcitriol can modulate insulin transcription. As previously mentioned, immune disorders lead to a general inflammatory state, which is an important element in the development of insulin resistance and diabetes type 2 . Interestingly, in placentas from women with gestational diabetes, VDR expression was higher than in healthy controls. In the same study, it was found that lower concentration of VD3 was associated with higher expression of VDR in the placenta [36]. There are many studies on VD3 concentration and supplementation on gestational diabetes occurrence. A meta-analysis from 2018, consisting of 87 observational studies and 25 randomized clinical trials, which included, respectively, 55,859 and 2,445 women, showed that in a group of women with gestational diabetes, VD3 serum concentration was lower than in a healthy control group [37]. The same meta-analysis regarding the effects of VD3 supplementation on pregnancy development found that it reduces the risk of gestational diabetes $[25,30]$, but also that some studies included found no influence [38].

While there is strong theoretical background, the effectiveness of VD3 supplementation on gestational diabetes is debatable.

\section{VD3 and preterm labor}

VD3 deficiency can affect preterm labor in two ways. Firstly, it reduces the body's defense capability, and secondly, it increases synthesis of pro-inflammatory cytokines. Uterine activity is probably triggered by genetic factors and pro-inflammatory cytokines. When they are activated before the fetus reaches maturity, preterm labor occurs. VD3 stimulates the innate immune system, which acts immediately after coming in contact with a pathogen. In experimental studies, calcitriol induces synthesis of cathelicidin (peptide of bactericidal properties) in myeloid cells, bronchial epithelial cells and keratinocytes. The immunostimulation by $25(\mathrm{OH}) \mathrm{D} 3$ also acts in an autocrine manner. Macrophages, after encountering a pathogen, increase the expression of VDR and CYP27B1 [39]. In many studies it has been demonstrated that VD3 deficiency can increase the risk of preterm birth. Among them, a study conducted by McDonnell et al. [40], showed that women with an optimal concentration of VD3 had $60 \%$ lower risk of preterm birth occurrence. In addition, a meta-analysis from 2017 suggested a possible correlation between VD3 deficiency and preterm birth, and a probable positive effect of VD3 supplementation on this pregnancy condition [41]. In the USA, the highest percentage of preterm births, $13.3 \%$, occurs among Afro-American women, in comparison to $9.0 \%$ in the Caucasian population. This difference is still seen after adjusting for socioeconomic factors. African-Americans also have five times greater risk of recurrent preterm birth. At the 
same time, in this group, VD3 deficiency occurs more often than in different ethnic groups $[42,43]$.

Presented studies are in favor that VD3 supplementation reduces the risk of preterm labor, however, we could not find specific recommendations on it.

\section{VD3 during lactation ad postpartum period}

The intake of 400 IU of VD3 is recommended for born in term infants between 0-6 months of life, independently to the way of the feeding, to prevent rickets. Exclusively breastfed infants are the group with the highest risk of vitamin D deficiency because $25(\mathrm{OH}) \mathrm{D} 3$ concentration in breast milk is only about $20 \%$ of mothers' serum concentration. So, to meet newborn requirements, mothers would have to have a serum concentration of VD3 much higher than it is usually recommended. The study of Hollis et al. [44], investigated this topic and concluded that a mother's intake of $6400 \mathrm{IU} /$ day safely supplies breast milk with $25(\mathrm{OH}) \mathrm{VD} 3$ to satisfy her nursing infant's requirements. Furthermore, another important issue of VD3 supplementation is prevention of pregnancy-associated osteoporosis. It is a rare syndrome affecting women during late pregnancy and the early post pregnancy period. It can cause severe loss of bone mineral density, pathological fractures in the vertebrae, hip and other bones. In the study of Eroglu et al. [45], the levels of $25(\mathrm{OH}) \mathrm{D} 3$, in postpartum women, were significantly lower in the low Bone Mineral Density group.

Proper VD3 supplementation during post-partum period is important in terms of prevention of infant rickets and mothers' osteoporosis in postpartum period.

\section{SUMMARY}

VD3 and VDR have an impact on pregnancy development in many areas. In early gestation they play a key role in the formation of the chorion, modulate the immune response, and regulate blood pressure and glucose tolerance. Contemporary lifestyle, which involves spending a long time indoors, because UVB radiation does not penetrate glass, makes VD3 skin synthesis difficult to occur in a sufficient amount. Nowadays, the Sars-CoV-2 pandemic can only increase the frequency of such a lifestyle. By proper VD3 supplementation and changes in lifestyle, it is possible to reduce the risk of many pregnancy complications. Treatment of VD3 deficiency should start at the time of pregnancy planning. The best way to treat VD3 deficiency is by dietary supplements. Because of high individual variability of skin synthesis, it is difficult to advise/prescribe a specified duration of sun exposure to treat VD3 deficiency [2]. VD3 supplementation in pregnancy seems to be a safe method to decrease VD3 deficiency, without side effects or intoxication. Many of the institutions give recommendations in this topic but they differ significantly in the advised dosage as listed in the Table 1. Most of them are consistent that a blood level of 25(OH)D3 above $30 \mathrm{ng} / \mathrm{mL}$ should be maintained [46, 47]. At the same time routine measurement of $25(\mathrm{OH}) \mathrm{D} 3$ is not advised, however, in our opinion it is worth to consider especially in a women with a higher risk of the pregnancy complications such as: RPL, PE, fetal growth disturbances, pregnancy diabetes and preterm labor. They might benefit the most of the VD3 supplementation adjusted to the serum level of $25(\mathrm{OH}) \mathrm{D} 3$.

\begin{tabular}{|c|c|c|c|c|}
\hline Date & Health Authority & $\begin{array}{l}\text { Dosage of VD3 } \\
\text { supplementation in IU daily }\end{array}$ & Comments & Citation \\
\hline 2011 & Endocrine Society & 600 & "in some cases at least 1500-2000 IU may be needed" & [46] \\
\hline 2011 & The Institute of Medicine & 600 & & [48] \\
\hline 2011 & $\begin{array}{l}\text { American College of Obstetricians } \\
\text { and Gynaecologists }\end{array}$ & 600 & 1000-2000 IU daily when VD3 deficiency is identified & [49] \\
\hline 2012 & The German Nutrition Society & 800 & & [50] \\
\hline 2014 & $\begin{array}{l}\text { Royal College of Obstetricians } \\
\text { and Gynaecologists }\end{array}$ & 400 & $\begin{array}{l}800 \text { IU daily, combined with calcium, } \\
\text { recommended for women at high risk } \\
\text { of PE } 1000 \text { IU daily recommended } \\
\text { for women at high risk of VD3 deficiency }{ }^{1}\end{array}$ & [26] \\
\hline 2016 & $\begin{array}{c}\text { The Scientific Advisory Comittee } \\
\text { on Nutrition }\end{array}$ & 400 & & [51] \\
\hline 2020 & $\begin{array}{l}\text { The Polish Society of Gynecologists } \\
\text { and Obstetrics }\end{array}$ & $1500-2000$ & $\begin{array}{l}\text { Women with a } \mathrm{BMI}>30 \mathrm{~kg} / \mathrm{m}^{2} \text { are advised } \\
\text { to consider a dosage of } 4000 \mathrm{IU} \text { daily }\end{array}$ & [47] \\
\hline 2020 & The World Health Organization & $\begin{array}{l}\text { Oral VD3 supplementation } \\
\text { is not recommended }\end{array}$ & $\begin{array}{l}\text { Women with suspected VD3 deficiency } \\
\text { are recommended to take } 200 \mathrm{IU} \text { daily }\end{array}$ & [52] \\
\hline
\end{tabular}

VD3 - vitamin D3; IU — international unit; BMI — body mass index; ${ }^{1}$ Women with increased skin pigmentation, reduced exposure to sunlight, or those who are socially excluded or obese 


\section{Conflict of interest}

The authors have no potential conflict of interests to declare.

\section{REFERENCES}

1. Holick MF. The vitamin D deficiency pandemic: Approaches for diagnosis, treatment and prevention. Rev Endocr Metab Disord. 2017; 18(2): 153165, doi: 10.1007/s11154-017-9424-1, indexed in Pubmed: 28516265.

2. Mendes MM, Darling AL, Hart KH, et al. Impact of high latitude, urban living and ethnicity on 25-hydroxyvitamin D status: A need for multidisciplinary action? J Steroid Biochem Mol Biol. 2019; 188: 95-102, doi: 10.1016/j.jsbmb.2018.12.012, indexed in Pubmed: 30610914.

3. Płudowski P, Ducki C, Konstantynowicz J, et al. Vitamin D status in Poland. Pol Arch MedWewn. 2016; 126(7-8):530-539, doi: 10.20452/pamw.3479, indexed in Pubmed: 27509842.

4. Weisman Y. Maternal, fetal and neonatal vitamin $D$ and calcium metabolism during pregnancy and lactation. Endocr Dev. 2003; 6: 34-49, doi: 10.1159/000072768, indexed in Pubmed: 12964424.

5. Díaz L, Sánchez I, Avila E, et al. Identification of a 25-hydroxyvitamin D3 1alpha-hydroxylase gene transcription product in cultures of human syncytiotrophoblast cells. J Clin Endocrinol Metab. 2000; 85(7): 2543-2549, doi: 10.1210/jcem.85.7.6693, indexed in Pubmed: 10902806.

6. Chan SY, Susarla R, Canovas D, et al. Vitamin D promotes human extravillous trophoblast invasion in vitro. Placenta. 2015; 36(4): 403-409, doi: 10.1016/j.placenta.2014.12.021, indexed in Pubmed: 25596923.

7. Zehnder D, Evans KN, Kilby MD, et al. The ontogeny of 25-hydroxyvitamin D(3) 1alpha-hydroxylase expression in human placenta and decidua. Am J Pathol. 2002; 161(1): 105-114, doi: 10.1016/s0002-9440(10)64162-4, indexed in Pubmed: 12107095.

8. Barrera D, Avila E, Hernandez G, et al. Calcitriol affects hCG gene transcription in cultured human syncytiotrophoblasts. Reprod Biol Endocrinol. 2008; 6: 3, doi: 10.1186/1477-7827-6-3, indexed in Pubmed: 18211694.

9. Barrera $D$, Avila $E$, Hernández $G$, et al. Estradiol and progesterone synthesis in human placenta is stimulated by calcitriol. J Steroid Biochem Mol Biol. 2007; 103(3-5): 529-532, doi: 10.1016/j.jsbmb.2006.12.097, indexed in Pubmed: 17257826.

10. King K, Smith S, Chapman M, et al. Detailed analysis of peripheral blood natural killer (NK) cells in women with recurrent miscarriage. Hum Reprod. 2010; 25(1): 52-58, doi: 10.1093/humrep/dep349, indexed in Pubmed: 19819893.

11. Lim KJ, Odukoya OA, Ajjan RA, et al. The role of T-helper cytokines in human reproduction. Fertil Steril. 2000; 73(1): 136-142, doi: 10.1016/s00150282(99)00457-4, indexed in Pubmed: 10632428.

12. Chu J, Gallos I, Tobias A, et al. Vitamin D and assisted reproductive treatment outcome: a systematic review and meta-analysis. Hum Reprod. 2018; 33(1): 65-80, doi: 10.1093/humrep/dex326, indexed in Pubmed: 29149263.

13. Ota $K$, Dambaeva $S$, Han AR, et al. Vitamin $D$ deficiency may be a risk factor for recurrent pregnancy losses by increasing cellular immunity and autoimmunity. Hum Reprod. 2014; 29(2): 208-219, doi: 10.1093/humrep/det424, indexed in Pubmed: 24277747.

14. Chen $X$, Yin $B$, Lian RC, et al. Modulatory effects of vitamin D on peripheral cellular immunity in patients with recurrent miscarriage. Am J Reprod Immunol. 2016; 76(6): 432-438, doi: 10.1111/aji.12585, indexed in Pubmed: 27696575.

15. Tavakoli M, Jeddi-Tehrani M, Salek-Moghaddam A, et al. Effects of 1,25(OH)2 vitamin D3 on cytokine production by endometrial cells of women with recurrent spontaneous abortion. Fertil Steril. 2011; 96(3): 751-757, doi: 10.1016/j.fertnstert.2011.06.075, indexed in Pubmed: 21880282.

16. Li N, Wu HM, Hang F, et al. Women with recurrent spontaneous abortion have decreased $25(\mathrm{OH})$ vitamin $\mathrm{D}$ and VDR at the fetal-maternal interface. Braz J Med Biol Res. 2017; 50(11): e6527, doi: 10.1590/1414431X20176527, indexed in Pubmed: 28902929.

17. Yan $X$, Wang L, Yan C, et al. Decreased expression of the vitamin D receptor in women with recurrent pregnancy loss. Arch Biochem Biophys. 2016; 606: 128-133, doi: 10.1016/j.abb.2016.07.021, indexed in Pubmed: 27477959.

18. Bender Atik R, Christiansen OB, Elson J, et al. ESHRE Guideline Group on RPL. ESHRE guideline: recurrent pregnancy loss. Hum Reprod Open. 2018; 2018(2): hoy004, doi: 10.1093/hropen/hoy004, indexed in Pubmed: 31486805.

19. Rylander A, Lindqvist PG. Eclampsia is more prevalent during the winter season in Sweden. Acta Obstet Gynecol Scand. 2011; 90(1): 114-117, doi: 10.1111/j.1600-0412.2010.01010.x, indexed in Pubmed: 21275925.
20. Akbari S, Khodadadi B, Ahmadi SA, et al. Association of vitamin D level and vitamin $D$ deficiency with risk of preeclampsia: A systematic review and updated meta-analysis. Taiwan J Obstet Gynecol. 2018; 57(2): 241-247, doi: 10.1016/j.tjog.2018.02.013, indexed in Pubmed: 29673668.

21. Li YC. Vitamin D regulation of the renin-angiotensin system. J Cell Biochem. 2003; 88(2): 327-331, doi: 10.1002/jcb.10343, indexed in Pubmed: 12520534 .

22. Tomaschitz A, Pilz S, Ritz E, et al. Independent association between 1,25-dihydroxyvitamin $D, 25$-hydroxyvitamin $D$ and the renin-angiotensin system: The Ludwigshafen Risk and Cardiovascular Health (LURIC) study. Clin Chim Acta. 2010; 411(17-18): 1354-1360, doi: 10.1016/j. cca.2010.05.037, indexed in Pubmed: 20515678.

23. Ma R, Gu Y, Zhao $S$, et al. Expressions of vitamin D metabolic components VDBP, CYP2R1, CYP27B1, CYP24A1, and VDR in placentas from normal and preeclamptic pregnancies. Am J Physiol Endocrinol Metab. 2012; 303(7): E928-E935, doi: 10.1152/ajpendo.00279.2012, indexed in Pubmed: 22871339.

24. Fogacci S, Fogacci F, Banach M, et al. Lipid and Blood Pressure Meta-analysis Collaboration (LBPMC) Group. Vitamin D supplementation and incident preeclampsia: A systematic review and meta-analysis of randomized clinical trials. Clin Nutr. 2020; 39(6): 1742-1752, doi: 10.1016/j.clnu.2019.08.015, indexed in Pubmed: 31526611.

25. Palacios C, Kostiuk LK, Peña-Rosas JP.Vitamin D supplementation for women during pregnancy. Cochrane Database Syst Rev. 2019; 7: CD008873, doi: 10.1002/14651858.CD008873.pub4, indexed in Pubmed: 31348529.

26. Royal College of Obstetricians and Gynecologists. Vitamin D in pregnancy. Scientific Impact Paper. 2014; 31(43).

27. Nguyen TPH, Yong HEJ, Chollangi T, et al. Placental vitamin D receptor expression is decreased in human idiopathic fetal growth restriction. J Mol Med (Berl). 2015; 93(7): 795-805, doi: 10.1007/s00109-015-1267-1, indexed in Pubmed: 25716068.

28. Hajianfar $\mathrm{H}$, Esmailzadeh A, Feizi A, et al. Association of maternal serum vitamin $D$ level with risk of pregnancy-related complications and neonatal anthropometric measures: a prospective observational study. Int J Prev Med. 2019; 10: 208, doi: 10.4103/ijpvm.IJPVM_543_17, indexed in Pubmed: 31921400.

29. Gernand AD, Simhan HN, Klebanoff MA, et al. Maternal serum 25-hydroxyvitamin $D$ and measures of newborn and placental weight in a U.S multicenter cohort study. J Clin Endocrinol Metab. 2013; 98(1): 398-404, doi: 10.1210/jc.2012-3275, indexed in Pubmed: 23162094.

30. Wei SQ, Qi HP, Luo ZC, et al. Maternal vitamin D status and adverse pregnancy outcomes: a systematic review and meta-analysis. J Matern Fetal Neonatal Med. 2013; 26(9): 889-899, doi: 10.3109/14767058.2013.765849, indexed in Pubmed: 23311886.

31. Eggemoen ÅR, Jenum AK, Mdala I, et al. Vitamin D levels during pregnancy and associations with birth weight and body composition of the newborn: a longitudinal multiethnic population-based study. Br J Nutr. 2017; 117(7): 985-993, doi: 10.1017/S000711451700068X, indexed in Pubmed: 28468694.

32. Roth $D E$, Leung $M$, Mesfin $E$, et al. Vitamin $D$ supplementation during pregnancy: state of the evidence from a systematic review of randomised trials. BMJ. 2017; 359: j5237, doi: 10.1136/bmj.j5237, indexed in Pubmed: 29187358.

33. BiWG, Nuyt AM, Weiler H, et al. Association between vitamin D supplementation during pregnancy and offspring growth, morbidity, and mortality: a systematic review and meta-analysis. JAMA Pediatr. 2018; 172(7):635-645, doi: 10.1001/jamapediatrics.2018.0302, indexed in Pubmed: 29813153.

34. Roth DE, Morris SK, Zlotkin S, et al. Vitamin D supplementation in pregnancy and lactation and infant growth. N Engl J Med. 2018; 379(6): 535-546, doi: 10.1056/NEJMoa1800927, indexed in Pubmed: 30089075.

35. Chiu KC, Chu A, Go VL, et al. Hypovitaminosis $D$ is associated with insulin resistance and beta cell dysfunction. Am J Clin Nutr. 2004; 79(5): 820-825, doi: 10.1093/ajcn/79.5.820, indexed in Pubmed: 15113720.

36. Knabl J, Hüttenbrenner R, Hutter $S$, et al. Gestational diabetes mellitus upregulates vitamin $D$ receptor in extravillous trophoblasts and fetoplacental endothelial cells. Reprod Sci. 2015; 22(3): 358-366, doi: 10.1177/1933719114542020, indexed in Pubmed: 25028176.

37. Zhang $Y$, Gong $Y$, Xue $H$, et al. Vitamin $D$ and gestational diabetes mellitus: a systematic review based on data free of Hawthorne effect. BJOG. 2018; 125(7): 784-793, doi: 10.1111/1471-0528.15060, indexed in Pubmed: 29244241.

38. Palacios C, De-Regil LM, Lombardo LK, et al. Vitamin D supplementation during pregnancy: Updated meta-analysis on maternal outcomes. J Steroid Biochem Mol Biol. 2016; 164: 148-155, doi: 10.1016/j. jsbmb.2016.02.008, indexed in Pubmed: 26877200. 
39. Adams JS, Hewison M. Unexpected actions of vitamin D: new perspectives on the regulation of innate and adaptive immunity. Nat Clin Pract Endocrinol Metab. 2008; 4(2): 80-90, doi: 10.1038/ncpendmet0716, indexed in Pubmed: 18212810.

40. McDonnell SL, Baggerly KA, Baggerly CA, et al. Maternal 25(OH)D concentrations $\geq 40 \mathrm{ng} / \mathrm{mL}$ associated with $60 \%$ lower preterm birth risk among general obstetrical patients at an urban medical center. PLoS One. 2017; 12(7): e0180483, doi: 10.1371/journal.pone.0180483, indexed in Pubmed: 28738090.

41. Zhou SS, Tao YH, Huang K, et al. Vitamin D and risk of preterm birth: Up-to-date meta-analysis of randomized controlled trials and observational studies. J Obstet Gynaecol Res. 2017; 43(2): 247-256, doi: 10.1111/jog.13239, indexed in Pubmed: 28150405.

42. Purisch SE, Gyamfi-Bannerman C. Epidemiology of preterm birth. Semin Perinatol. 2017; 41(7): 387-391, doi: 10.1053/j.semperi.2017.07.009, indexed in Pubmed: 28865982.

43. Yao S, Hong CC, Bandera EV, et al. Demographic, lifestyle, and genetic determinants of circulating concentrations of 25-hydroxyvitamin D and vitamin D-binding protein in African American and European American women. Am J Clin Nutr. 2017; 105(6): 1362-1371, doi: 10.3945/ajcn.116.143248, indexed in Pubmed: 28424184.

44. Hollis BW, Wagner CL, Howard CR, et al. Maternal versus infant vitamin D supplementation during lactation: a randomized controlled trial. Pediatrics. 2015; 136(4): 625-634, doi: 10.1542/peds.2015-1669.

45. Eroglu S, Karatas G, Aziz V, et al. Evaluation of bone mineral density and its associated factors in postpartum women. Taiwan J Obstet Gy- necol. 2019; 58(6): 801-804, doi: 10.1016/j.tjog.2019.09.013, indexed in Pubmed: 31759531.

46. Holick MF, Binkley NC, Bischoff-Ferrari HA, et al. Endocrine Society. Evaluation, treatment, and prevention of vitamin $D$ deficiency: an Endocrine Society clinical practice guideline. J Clin Endocrinol Metab. 2011; 96(7): 1911-1930, doi: 10.1210/jc.2011-0385, indexed in Pubmed: 21646368.

47. Zimmer M, Sieroszewski P, Oszukowski P, et al. Rekomendacje Polskiego Towarzystwa Ginekologów i Położników dotyczące suplementacji u kobiet ciężarnych. https://www.ptgin.pl/sites/default/files/page-2020/REKOMENDACJE\%20PTGIP\%20SUPLEMENTY\%20 W\%20Cl\%C4\%84\%C5\%BBY\%202020-07-28\%20bo.pdf (2020-07-08).

48. Ross A, Manson J, Abrams S, et al. The 2011 report on dietary reference intakes for calcium and vitamin $D$ from the Institute of Medicine: what clinicians need to know. The Journal of Clinical Endocrinology \& Metabolism. 2011; 96(1): 53-58, doi: 10.1210/jc.2010-2704.

49. American College of Obstetricians and Gynecologists. Vitamin D: screening and supplementation during pregnancy. Committee Opinion. 2011;495.

50. Koletzko B, Bauer $C P$, Bung $P$, et al. German national consensus recommendations on nutrition and lifestyle in pregnancy by the ,Healthy Start - Young Family Network'. Ann Nutr Metab. 2013; 63(4): 311-322, doi: 10.1159/000358398, indexed in Pubmed: 24514069.

51. SACN vitamin D and health report. https://www.gov.uk/government/publications/sacn-vitamin-d-and-health-report (2020-12-15).

52. WHO antenatal care recommendations for a positive pregnancy experience. Nutritional interventions update: Vitamin D supplements during pregnancy Geneva, 2020. 